\title{
Prevalence, incidence and outcomes of diabetes in Ontario First Nations children: a longitudinal population-based cohort study
}

\author{
Rayzel Shulman MD PhD, Morgan Slater PhD, Shahriar Khan MSc, Carmen Jones BA, \\ Jennifer D. Walker PhD, Kristen Jacklin PhD, Michael E. Green MD MPH, Eliot Frymire MA, \\ Baiju R. Shah MD PhD
}

See related research article at www.cmajopen.ca/lookup/doi/10.9778/cmajo.20190096

Abstract

Background: First Nations people are known to have a higher risk of childhood-onset type 2 diabetes, yet population-level data about diabetes in First Nations children are unavailable. In a partnership between Chiefs of Ontario and academic researchers, we describe the epidemiologic features and outcomes of diabetes in First Nations children in Ontario.

Methods: We created annual cohorts from 1995/96 to 2014/15 using data from the Registered Persons Database linked with the federal Indian Register. We used the Ontario Diabetes Database to identify children with all types of diabetes and calculated the prevalence and incidence for First Nations children and other children in Ontario. We describe glycemic control in First Nations children and other children in 2014.

Results: In 2014/15, there were 254 First Nations children and 10144 other children with diagnosed diabetes in Ontario. From $1995 / 96$ to $2014 / 15$, the prevalence increased from 0.17 to 0.57 per 100 children, and the annual incidence increased from 37 to 94 per 100000 per year among First Nations children. In 2014/15, the prevalence of diabetes was 0.62/100 among First Nations girls and $0.36 / 100$ among other girls. The mean glycosylated hemoglobin level among First Nations children was $9.1 \%$ (standard deviation $2.7 \%$ ) and for other children, $8.5 \%$ (standard deviation $2.1 \%$ ).

Interpretation: First Nations children have substantially higher rates of diabetes than non-Aboriginal children in Ontario; this is likely driven by an increased incidence of type 2 diabetes and increased risk for diabetes among First Nations girls. There is an urgent need for strategies to address modifiable factors associated with the risk of diabetes, improve access to culturally sensitive diabetes care and improve outcomes for First Nations children.

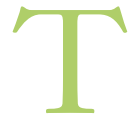

he prevalence of type 2 diabetes in children is increasing worldwide. ${ }^{1-3}$ In 2006-2008, the incidence of childhood-onset type 2 diabetes in Canada was estimated at 1.54 per 100000 per year, with the highest incidence in Manitoba (12.45 per 100000 per year); in Ontario, the incidence was 1.7 per 100000 per year. ${ }^{4}$ First Nations children in Canada have the highest incidence of type 2 diabetes, at 23.2 per 100000 per year. ${ }^{4}$ In Manitoba and northwestern Ontario, $87 \%$ of children with type 2 diabetes have First Nations heritage. ${ }^{5}$ First Nations status and exposure to diabetes in utero are independently associated with an increased risk of type 2 diabetes in the first 30 years of life. ${ }^{6,7}$ This is especially concerning because youth with type 2 diabetes experience complications sooner than youth with type 1 diabetes. ${ }^{8,9}$
The prevalence, incidence and outcomes of diabetes among First Nations children in Ontario are not known. It is important for First Nations communities to have these data to inform population approaches to prevent and manage diabetes

Competing interests: Michael Green reports a grant from the Ontario SPOR SUPPORT Unit during the conduct of the study and consulting fees from the First Nations and Inuit Health Branch, Health Canada outside the submitted work. No other competing interests were declared.

This article has been peer reviewed.

Correspondence to: Rayzel Shulman, Rayzel.shulman @ sickkids.ca CMAJ Open 2020. DOI:10.9778/cmajo.20190226 
now and to plan for the future. ${ }^{10}$ Comparing diabetes in First Nations children to that in other children in Ontario is also important as we consider how diabetes affects First Nations people differently from other people in Ontario.

In this paper, we describe the change in prevalence and incidence of diabetes over time among First Nations children compared to other children in Ontario. We also explore differences in visits to pediatricians or endocrinologists, and adherence to screening guidelines for retinopathy and glycemic control for First Nations children with diabetes compared to other children with diabetes in Ontario.

\section{Methods}

\section{Setting and data sources}

This was a population-based longitudinal cohort study using health administrative databases in Ontario. We have described the details of the research partnership and the detailed methods of our use of the health administrative data held at ICES elsewhere. ${ }^{11,12}$ Annual cross-sectional cohorts over a 20-year period from Apr. 1, 1995, to Mar. 31, 2015, were created. All people from the Registered Persons Database who were Ontario residents, were eligible for a health card, had had contact with the health care system within the previous 7 years and were 19 years of age or less were included. We defined this age group to be consistent with the study used to validate the definition for the pediatric Ontario Diabetes Database. ${ }^{13}$

First Nations children were identified by linking the federal Indian Register (which includes all people registered with the federal government as a "Status Indian" under the Indian Act ${ }^{14}$ ) with the Registered Persons Database. We used the pediatric Ontario Diabetes Database, a validated registry of all Ontario residents with a diagnosis of all types of diabetes before age 19 years (83\% sensitivity, $99 \%$ specificity), to identify children with diabetes. ${ }^{13} \mathrm{~A}$ description of the data sets accessed are available in Appendix 1 of our companion methods paper. ${ }^{12}$

We assumed that First Nations children with diabetes have type 2, since type 1 diabetes is relatively uncommon in First Nations children. For example, in Manitoba, $17 \%$ of children (<18 yr of age) are First Nations people, whereas only $5 \%$ of children with type 1 diabetes are First Nations. ${ }^{15}$ Furthermore, we assumed that most of the other children in Ontario with diabetes have type 1 because we have previously shown that almost all $(94.8 \%)$ children in Ontario with diabetes have type $1 .^{16}$

\section{Outcome measures}

We estimated the crude prevalence of diabetes in annual cohorts from 1995/96 to 2014/15 among First Nations children and other children in Ontario. The numerator included children who were alive and identified through the pediatric Ontario Diabetes Database as having been diagnosed with diabetes by the end of each year. We calculated annual crude incidence rates of diabetes for the study period for First Nations children and other children. The numerator included all newly diagnosed cases of diabetes according to the Ontario Diabetes Database in a particular year; all those who had no previous diagnosis of diabetes and were alive at the end of the fiscal year were included in the denominator. We also estimated the prevalence and incidence of diabetes among First Nations and other children by sex.

We ascertained outpatient visits with a pediatrician or endocrinologist in 2014/15 using the Ontario Health Insurance Plan Database (physician billing claims) to identify visits for routine diabetes care. Guidelines recommend that all children with diabetes should have access to an experienced pediatric diabetes health care team and specialized care. ${ }^{17,18}$ Since 2001, in Ontario, care for children with diabetes is coordinated by the Ontario Pediatric Diabetes Network (formerly the Network of Ontario Pediatric Diabetes Programs). In 2012, all but 1 of the 35 centres was staffed, at least part-time, by a pediatrician or an endocrinologist. ${ }^{16}$ For this reason, we opted to ascertain outpatient visits with a pediatrician or endocrinologist to measure visits for routine diabetes care. To avoid inappropriately counting primary or urgent-carerelated visits that were not for routine diabetes care but were nonetheless coded as a diabetes visit, we did not include visits with a diagnostic code for diabetes to a family physician. We used the Ontario Laboratories Information System (OLIS), which contains data from community and hospitals laboratories, to identify children with at least 1 glycosylated hemoglobin $\left(\mathrm{HbA}_{\mathrm{lc}}\right)$ test completed in $2014 / 15 .{ }^{19} \mathrm{We}$ determined the proportion of children aged 5 years or less, 6-12 years and 13-19 years who had at least $1 \mathrm{HbA}_{\mathrm{cc}}$ level available in OLIS in 2014/15. Based on the 2013 Canadian Diabetes Association Guideline, the $\mathrm{HbA}_{\mathrm{lc}}$ target for adolescents aged 13-18 years was $7.0 \%$ or less. ${ }^{17}$ Therefore, for this age group, we categorized $\mathrm{HbA}_{1 \mathrm{c}}$ levels as good $(<7.0 \%)$, fair $(7.0 \%-8.5 \%)$ or poor (> 8.5\%).

According to the 2013 Canadian Diabetes Association guidelines, annual screening for retinopathy should be performed in children with type 2 diabetes from the time of diagnosis and in children with type 1 diabetes who are more than 15 years old beginning 5 years after diagnosis. ${ }^{17,18} \mathrm{We}$ determined the proportion of children aged 16 or 17 with diabetes for 5 years or more who had had an eye examination in the 2 years before 2014/15. We identified eye examinations through billing claims from ophthalmologists or optometrists, including telemedicine care. ${ }^{20}$ Visits to any retinal screening programs operating in First Nations communities would have been reviewed remotely by an ophthalmologist and therefore would be captured by the telemedicine codes.

We determined rurality using the Rurality Index for Ontario (RIO), a score based on community characteristics including access to health care services. ${ }^{21}$ We used 4 categories to describe rurality: urban (RIO score 0-9), semiurban (RIO score 10-39), rural (RIO score $\geq 40$ ) and "remote" (no RIO score). ${ }^{12}$

\section{Statistical analysis}

Crude prevalence and annual crude incidence rates for First Nations children and other children were reported. We conducted all analyses using SAS Enterprise Guide version 7.1 (SAS Institute). 


\section{Ethics approval}

The project received approval from the Chiefs of Ontario Data Governance Committee and the research ethics boards of Queen's University and Laurentian University.

\section{Results}

In 2014/15, there were 254 First Nations children and 10144 other children with diagnosed diabetes in Ontario. The characteristics of the 2014/15 cohort are presented in Table 1. Of First Nations children with diabetes, 136 (53.5\%) were girls, $\geq 197(\geq 77.6 \%$ ) were aged $13-19$ years, and 55 $(21.6 \%)$ lived in a rural area, versus $4843(47.7 \%), 6476$ $(63.8 \%)$ and $741(7.3 \%)$, respectively, of other children in with diabetes. Seventy (27.6\%) First Nations children with diabetes versus $44(0.4 \%)$ other children with diabetes were assigned a rurality score of remote.

In 1995/96, the overall prevalence of diabetes was similar in the 2 populations, but it diverged over time, and, in 2014/15, the prevalence of diabetes among First Nations children was more than $50 \%$ greater than among other children. Over the study period, among First Nations children, the prevalence of diabetes increased from $0.17(95 \%$ confidence interval [CI] $0.14-0.21$ ) to 0.57 (95\% CI 0.50 $0.64)$ per 100 children, and the annual incidence from 37 (95\% CI 22-58) to 94 (95\% CI 67-127) per 100000 per year. Among other children, the incidence of the disease increased from 23 (95\% CI 21-24) to 46 (95\% CI 43-48) per 100000 per year over the study period. The crude overall and sex-specific prevalence and incidence of diabetes in First Nations children and other children from 1995/96 to 2014/15 are shown in Figures 1 and 2, respec- tively. In 2014/15, the prevalence of diabetes was $0.62 / 100$ in First Nations girls and 0.36/100 in other girls.

In 2014/15, 93 (36.6\%, 95\% CI 29.9-44.2) First Nations children with diabetes versus 6441 (63.5\%, 95\% CI 62.0$65.0)$ other children had at least 1 visit to a pediatrician or endocrinologist. Among other children, use of specialists was similar regardless of where they lived; however, for First Nations children, there were differences across rurality levels: $42(56.0 \%, 95 \%$ CI $41.1-74.8)$ of those living in urban areas had at least 1 visit, versus 13 (18.6\%, 95\% CI 10.1-30.9) of those living in remote areas (Figure 3).

Among children aged 13-19 years with prevalent diabetes, $48.0 \%$ (number suppressed to comply with privacy legislation that does not permit reporting of cell sizes $<6$ or facilitate the calculation of cell sizes $<6$ ) of First Nations children and 3277 other children $(50.6 \%)$ had at least 1 $\mathrm{HbA}_{\mathrm{lc}}$ test result available in OLIS in 2014/15. The corresponding values for children less than 13 years were 26 $(48.1 \%)$ and 1218 (33.2\%). Owing to the relatively low proportion of available data for children less than 13 years, we report the $\mathrm{HbA}_{\mathrm{lc}}$ values for children aged 13-19 only. The distribution of $\mathrm{HbA}_{\mathrm{cc}}$ results for children in this age group with available data is displayed in Figure 4. In 2014/15, for children aged 13-19 who had a result available in OLIS, the mean $\mathrm{HbA}_{1 \mathrm{c}}$ value for First Nations children was 9.1\% (standard deviation [SD] 2.7\%) and for other children, $8.5 \%$ (SD 2.1\%).

In 2014/15, among children aged 16 or 17 with diabetes for 5 years or more, 15/21 First Nations children $(71.4 \%$, 95\% CI 40.0-100.0) and 758/1004 other children (75.5\%, $95 \%$ CI 70.2-81.1) had had at least 1 eye examination in the previous 2 years.

\begin{tabular}{|c|c|c|c|c|}
\hline \multirow[b]{2}{*}{ Characteristic } & \multicolumn{2}{|c|}{ First Nations children, no. (\%) } & \multicolumn{2}{|c|}{ Other children, no. (\%) } \\
\hline & $\begin{array}{l}\text { With diabetes } \\
\quad n=254\end{array}$ & $\begin{array}{c}\text { Total population } \\
n=44856\end{array}$ & $\begin{array}{c}\text { With diabetes } \\
n=10144\end{array}$ & $\begin{array}{c}\text { Total population } \\
n=2829983\end{array}$ \\
\hline \multicolumn{5}{|l|}{ Sex } \\
\hline Male & $118(46.5)$ & $23011(51.3)$ & $5301(52.3)$ & $1451510(51.3)$ \\
\hline Female & $136(53.5)$ & 21845 (48.7) & $4843(47.7)$ & $1378473(48.7)$ \\
\hline \multicolumn{5}{|l|}{ Age group, yr } \\
\hline$\leq 5$ & $\leq 5^{*}$ & $7042(15.7)$ & $672(6.6)$ & $703443(24.9)$ \\
\hline $6-12$ & $52(20.5)$ & $17867(39.8)$ & $2996(29.5)$ & $1040582(36.8)$ \\
\hline $13-19$ & $\geq 197^{*}$ & $19947(44.5)$ & $6476(63.8)$ & $1085958(38.4)$ \\
\hline \multicolumn{5}{|l|}{ Rurality } \\
\hline Urban & $75(29.5)$ & $12832(28.6)$ & $7170(70.7)$ & $2102167(74.3)$ \\
\hline Semiurban & $54(21.3)$ & $8096(18.0)$ & $2189(21.6)$ & $533306(18.8)$ \\
\hline Rural & $55(21.6)$ & $10042(22.4)$ & $741(7.3)$ & $180874(6.4)$ \\
\hline Remote & $70(27.6)$ & 13886 (31.0) & $44(0.4)$ & $13636(0.5)$ \\
\hline
\end{tabular}




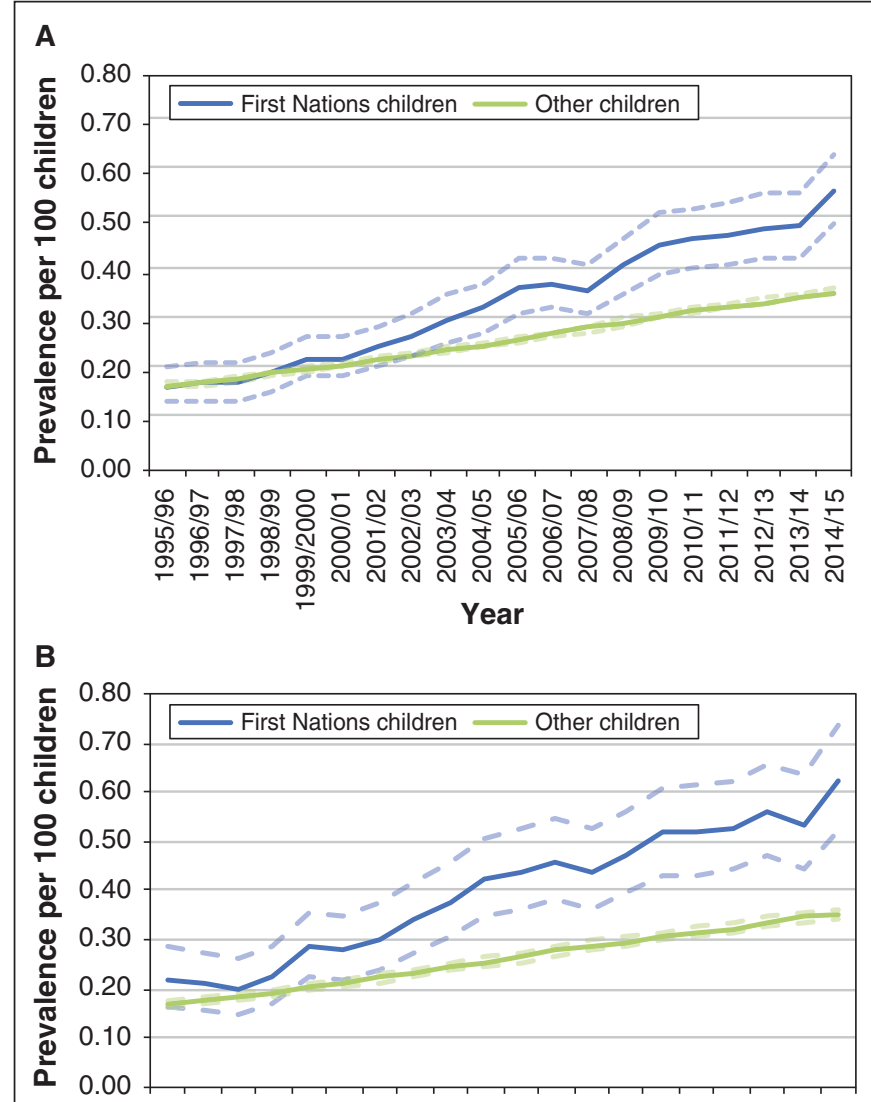

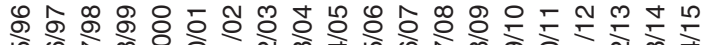

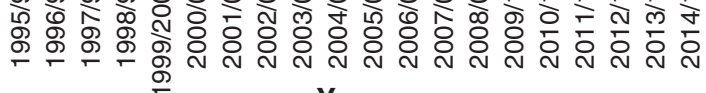
Year

C

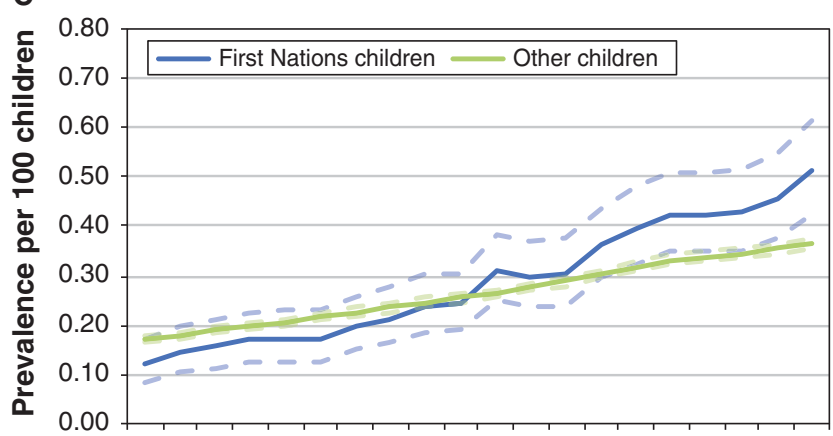

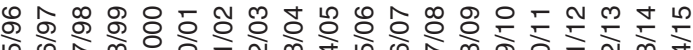

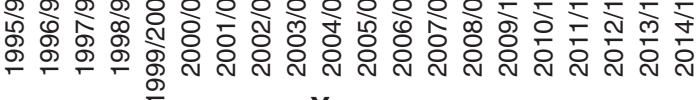
Year

Figure 1: Crude prevalence of diabetes per 100 children aged 19 years or less overall $(A)$ and among girls (B) and boys (C), among First Nations children and other children in Ontario, 1995/96-2014/15. Dotted lines represent $95 \%$ confidence intervals.

\section{Interpretation}

We found that First Nations children in Ontario had a high prevalence of diabetes, likely largely driven by an increasing incidence of type 2 diabetes. The divergence in

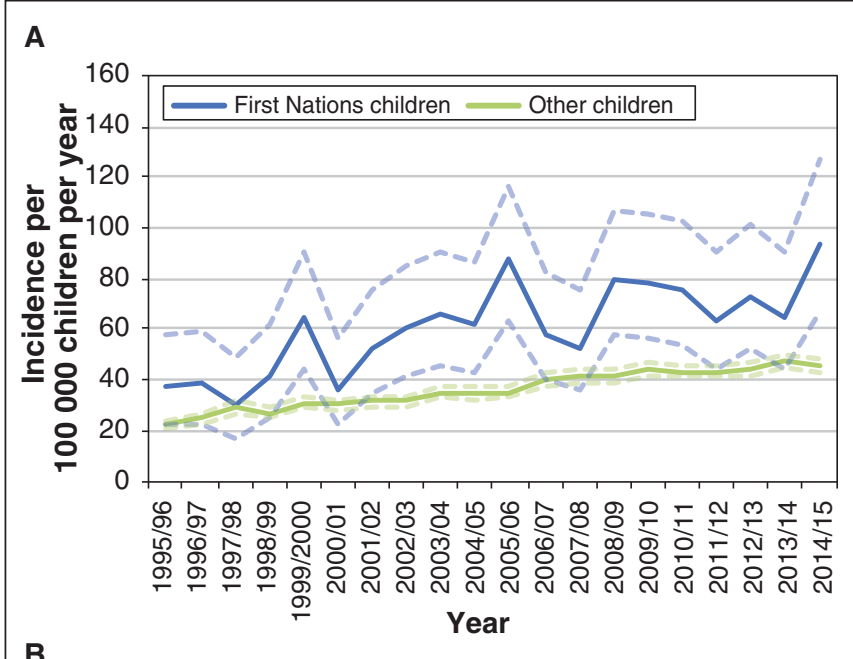

B

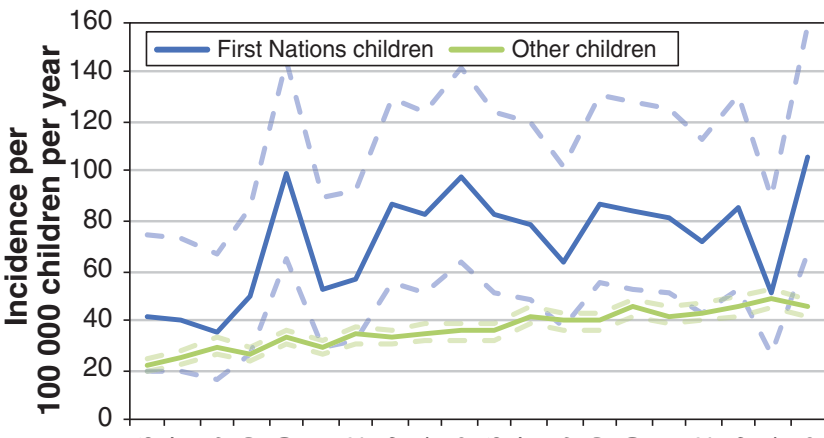

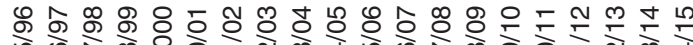

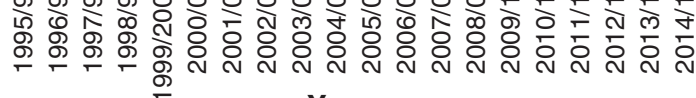
Year

C

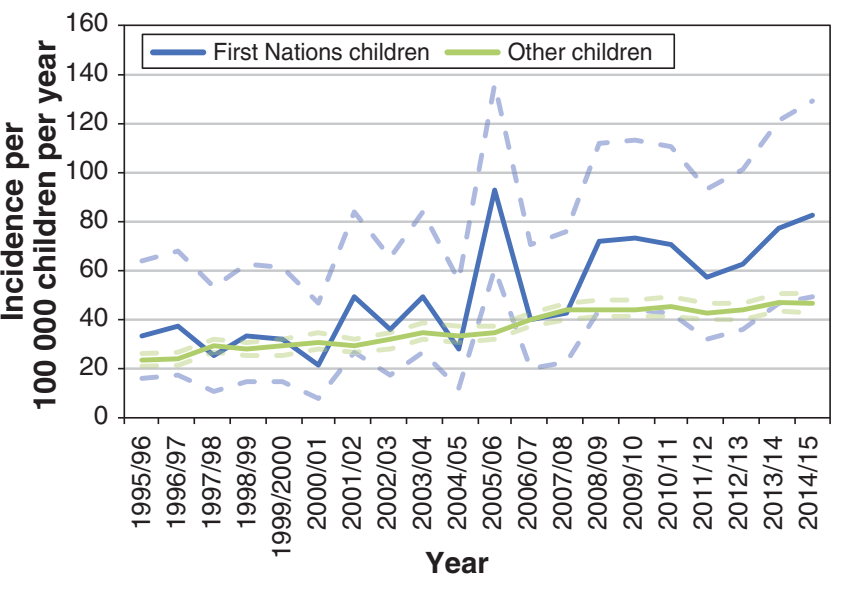

Figure 2: Crude incidence of diabetes per 100000 children per year aged 19 years or less overall $(A)$ and among girls (B) and boys (C), among First Nations children and other children, 1995/96-2014/15. Dotted lines represent $95 \%$ confidence intervals.

the prevalence of diabetes between First Nations children and other children in the province from 1995/96 to $2014 / 15$ is striking. It was driven by a particularly increased risk of diabetes among First Nations girls, who had nearly double the diabetes prevalence of non-Aboriginal girls. 


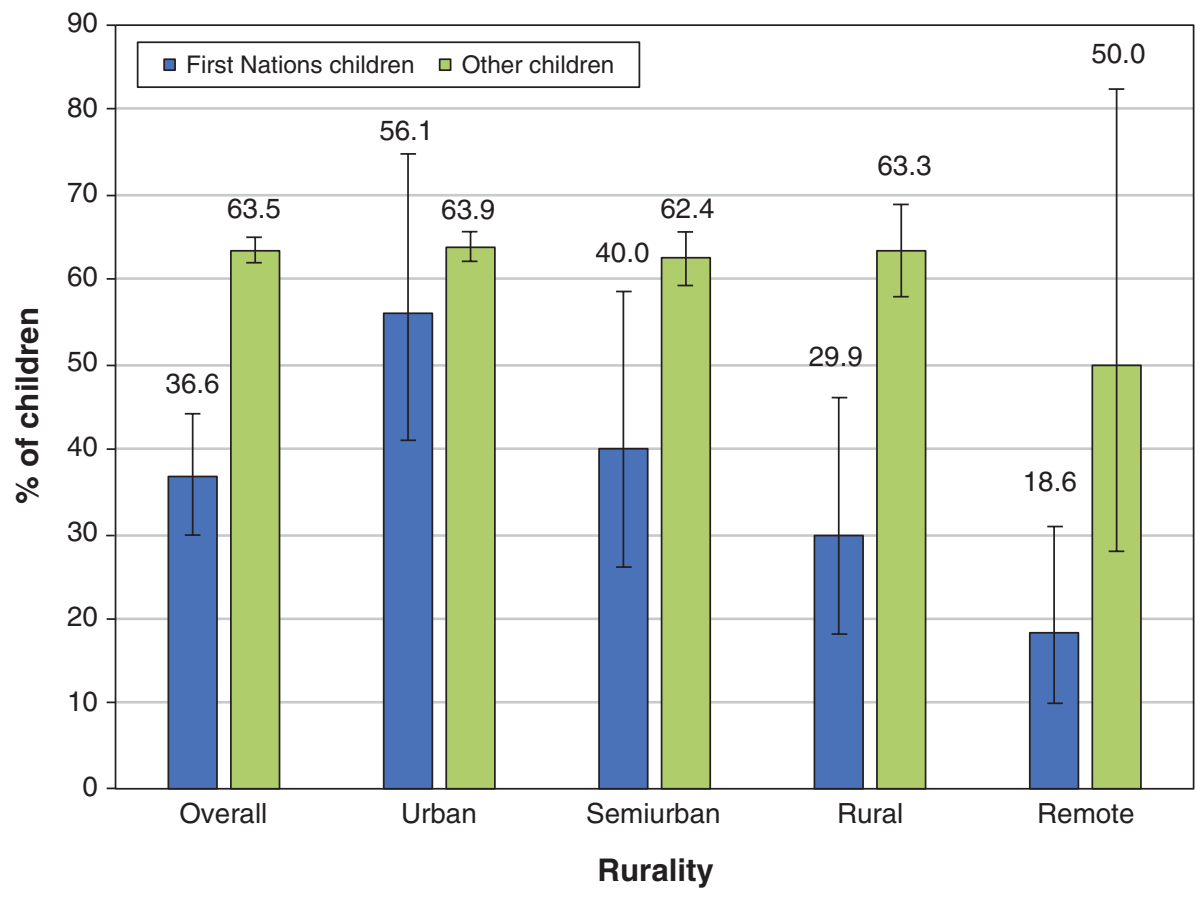

Figure 3: Proportion of children with diabetes who had at least 1 visit to a pediatrician or endocrinologist in the previous year for a diagnosis of diabetes among First Nations children $(n=93)$ and other children $(n=6441)$ by level of rurality, 2014/15. Error bars represent $95 \%$ confidence intervals.

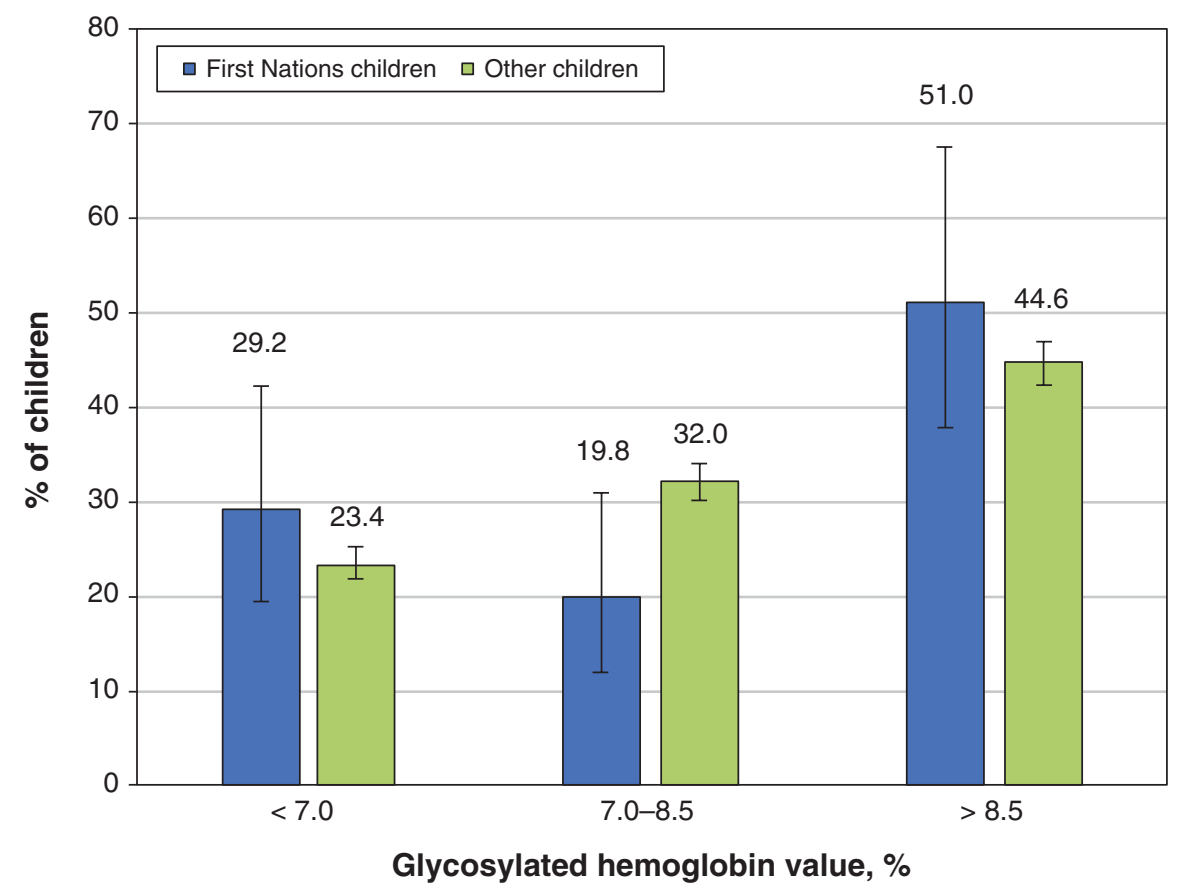

Figure 4: Proportion of First Nations children $(n=96)$ and other children $(n=3277)$ aged $13-19$ years with diabetes who had a glycosylated hemoglobin test result in the Ontario Laboratories Information System, by glycosylated hemoglobin category, 2014/15. Error bars represent $95 \%$ confidence intervals. 
There was an increase in the incidence of diabetes among First Nations children over the study period.

A similar increasing trend in the incidence of type 2 diabetes among children from 2006 to 2011 was reported in Manitoba, where $87 \%$ of children with diabetes had First Nations heritage. ${ }^{5}$ The prevalence (0.27/100) and incidence (59/100 000 per year) of all types of diabetes in Aboriginal youth in Alberta in $2007^{22}$ are similar to what we report in Ontario. Native American children in the United States, ${ }^{2}$ Aboriginal children in Canada ${ }^{4}$ and First Nations children in Manitoba ${ }^{5}$ have a higher incidence of type 2 diabetes than children in the general population. Notably, a 2006-2008 Canadian national surveillance study of children less than 18 years showed an observed minimal incidence of type 2 diabetes among Aboriginal children of 23.2/100 000 per year, compared to 2.34/100 000 per year among all Canadian children. ${ }^{4}$ Our finding that there was a higher prevalence of diabetes among First Nations girls than non-Aboriginal girls in Ontario is consistent with the findings from a population-based Manitoba study showing that, of 387 adolescents with childhood-onset type 2 diabetes, $61.8 \%$ were girls. ${ }^{23}$

Our results also show that First Nations children with diabetes in Ontario, especially those living in rural areas, were not receiving diabetes care as recommended by clinical practice guidelines. The 2013 Canadian Diabetes Association guidelines recommended that children with type 2 diabetes should receive care in conjunction or consultation with an interdisciplinary pediatric diabetes health care team. ${ }^{18}$ The updated Diabetes Canada 2018 guidelines for children with type 2 diabetes specify that care should be provided by an interprofessional pediatric diabetes health care team that should include a pediatric endocrinologist or a pediatrician with diabetes expertise. ${ }^{24}$ Despite the existence of the Ontario Pediatric Diabetes Network, established in 2001, to provide access to specialized pediatric diabetes care, ${ }^{25}$ some of the centres in northern Ontario serving children with type 2 diabetes do not have access to physicians with specialized training in pediatric diabetes. ${ }^{16}$

Children in the general population of Ontario with all types of diabetes may not be receiving the recommended care outlined in clinical practice guidelines. We are not aware of existing Canadian data on specialist diabetes care for children with type 2 diabetes specifically; however, a population-based study from British Columbia showed that, among people aged 1-24 years with type 1 diabetes, there was poor adherence to guidelines $\left(<2\right.$ diabetes-related physician visits or $<2 \mathrm{HbA}_{\mathrm{lc}}$ tests per year) in $54 \%$ of all person-years. ${ }^{26}$ Of 7233 people aged less than 21 years with newly diagnosed type 2 diabetes enrolled in a US managed-care network from 2001 to 2014, only $42.2 \%$ had undergone an eye examination by 6 years after initial diabetes diagnosis. ${ }^{27}$ Data from Manitoba show that the rates of retinopathy in youth-onset type 2 diabetes begin to increase rapidly after 10 years of diabetes duration (by 20 years, almost $75 \%$ had retinopathy); this underscores the potential importance of early screening. ${ }^{8}$

In the current study, the mean $\mathrm{HbA}_{\mathrm{lc}}$ value for First Nations children was 9.1\% (SD 2.7\%) and for other children, 8.5\% (SD 2.1\%). Similarly, in Manitoba, children aged 1-18 with type 2 diabetes (the majority of whom were of self- declared Aboriginal heritage) had a higher mean $\mathrm{HbA}_{\mathrm{lc}}$ value than those with type 1 diabetes $(9.2 \%$ [SD 2.3\%] v. 8.9\% [SD $3.0 \%$ ], $p=0.04) .{ }^{8}$ In the current study, only $29.2 \%$ of First Nations children and $23.4 \%$ of other children aged $13-19$ met the 2013 Canadian Diabetes Association $\mathrm{HbA}_{\mathrm{lc}}$ target of less than $7.0 \% .^{17,18}$ More than half of First Nations children had an $\mathrm{HbA}_{\mathrm{Ic}}$ level greater than $8.5 \%$, which put them at increased risk for both acute and chronic diabetes complications. This is especially concerning because the risk of complications is higher for youth with type 2 diabetes than for those with type 1 diabetes. ${ }^{8}$

Known risk factors for youth-onset type 2 diabetes include obesity, family history of type 2 diabetes, being a member of an ethnic group at high risk, nonalcoholic fatty liver disease and evidence of insulin resistance. ${ }^{28}$ Exposure to maternal pregestational and gestational diabetes is known to increase the risk of youth-onset type 2 diabetes in First Nations children. ${ }^{6,23,28,29}$ Some Oji-Cree First Nations children in Manitoba with early-onset type 2 diabetes were found to have a hepatocyte nuclear factor 1- $\alpha$ G319S mutation, associated with an insulin-secretory defect. ${ }^{30}$

Some of these risk factors are modifiable and could be targeted in efforts to prevent youth-onset type 2 diabetes. Peer mentoring to promote healthy living was shown to reduce weight gain and improve knowledge about healthy living in children in a remote, isolated First Nation community. ${ }^{31}$ Early screening for diabetes in pregnancy and close follow-up of offspring of women with gestational or preexisting type 2 diabetes may help to mitigate the known increased risk of early-onset type 2 diabetes in those exposed to diabetes in utero. ${ }^{6,7}$ Importantly, strategies to prevent gestational diabetes and type 2 diabetes in young women could subsequently reduce the risk of type 2 diabetes in their offspring. ${ }^{6,7}$

Possible factors to explain the observed disparity in access to care and outcomes of diabetes in First Nations children include poverty, food insecurity and mental health challenges that make it difficult to access care and adopt behavioural lifestyle changes essential to the clinical management of type 2 diabetes. ${ }^{8,32,33}$ Furthermore, trauma, colonization and social exclusion experienced by First Nations children and their families is a barrier to accessing health care and establishing trust and a therapeutic relationship with health care providers. ${ }^{34}$ Strategies to overcome these barriers such as promoting wellness and positive mental health could facilitate improved self-management of type 2 diabetes in First Nations youth. The stigma associated with type 2 diabetes is also known to be a barrier to well-being and can be reduced with greater social support. ${ }^{35}$

\section{Limitations}

There are notable limitations of our administrative data sets. ${ }^{12}$ There may be people missing from our population-based cohorts created with the use of the Registered Persons Database; this may have led to an overestimation of the rates of diabetes in some regions. It is possible that we underestimated the number of First Nations children with diabetes because our cohort included only those registered as Status First Nations with the federal government. ${ }^{14}$ First Nations children 
are typically registered at birth but can be registered at any age. The proportion of First Nations children who are registered is unknown. Furthermore, care delivered in Aboriginal Health Access Centres or in Winnipeg is not captured in Ontario administrative data. In 2014, there were 77 children living in northwestern Ontario who received diabetes care in Winnipeg. ${ }^{36}$

The Ontario Diabetes Database case definition includes the diagnostic code 250, which does not differentiate between types of diabetes. There is no validated algorithm for identifying children with specific types of diabetes with the use of administrative data. Furthermore, the validity of the Ontario Diabetes Database algorithm has not been tested in First Nations populations. We were unable to report socioeconomic status because income quintiles, a commonly used proxy for individual socioeconomic status, are not accurate for First Nations populations. ${ }^{37}$

In Ontario, annual eye examinations for people with diabetes and all children are covered by the Ontario Health Insurance Plan. Therefore, it is unlikely that children in our study would have eye examinations reimbursed by private insurance, which would not be captured in billing data. Routine diabetes care visits with a family physician or diabetes nurse educator were not captured because we focused on specialist care from a pediatrician or endocrinologist. Finally, OLIS contains data from community laboratories, but enrolment of hospitals to contribute to OLIS has been more gradual over time. The addition of hospital laboratory data to OLIS was implemented on a regional basis, with the most recent addition from the north and northwest of the province, where there is a large First Nations population. Major pediatric hospitals such as The Hospital for Sick Children and the Children's Hospital of Eastern Ontario did not contribute to OLIS in 2014, nor does OLIS include data from point-of-care $\mathrm{HbA}_{\mathrm{lc}}$ testing. ${ }^{19}$ Despite this, approximately equal proportions of First Nations children and other children aged 13-19 had $\mathrm{HbA}_{\mathrm{lc}}$ values available in OLIS. However, given that only about half of children with diabetes in either cohort had $\mathrm{HbA}_{1 \mathrm{c}}$ values available, it is possible that the $\mathrm{HbA}_{\mathrm{lc}}$ values that we report do not represent those of the entire population of both First Nations children and other children with diabetes.

\section{Conclusion}

First Nations children in Ontario had a high prevalence of diabetes, likely largely driven by an increasing incidence of type 2 diabetes. Our findings highlight an urgent need to reduce disparities in modifiable risk factors for diabetes, use of health care services to manage diabetes and diabetes outcomes for First Nations children.

\section{References}

1. Pinhas-Hamiel O, Zeitler P. The global spread of type 2 diabetes mellitus in children and adolescents. 7 Pediatr 2005;146:693-700.

2. Mayer-Davis EJ, Lawrence JM, Dabelea D, et al.; SEARCH for Diabetes in Youth Study. Incidence trends of type 1 and type 2 diabetes among youths, 2002-2012. N Engl 7 Med 2017;376:1419-29.

3. Dabelea D, Mayer-Davis EJ, Saydah S, et al.; SEARCH for Diabetes in Youth Study. Prevalence of type 1 and type 2 diabetes among children and adolescents from 2001 to 2009. 7AMA 2014;311:1778-86.
4. Amed S, Dean HJ, Panagiotopoulos C, et al. Type 2 diabetes, medicationinduced diabetes, and monogenic diabetes in Canadian children: a prospective national surveillance study. Diabetes Care 2010;33:786-91.

5. Sellers EAC, Wicklow BA, Dean HJ. Clinical and demographic characteristics of type 2 diabetes in youth at diagnosis in Manitoba and northwestern Ontario (2006-2011). Can 7 Diabetes 2012;36:114-8.

6. Sellers EA, Dean HJ, Shafer LA, et al. Exposure to gestational diabetes mellitus: impact on the development of early-onset type 2 diabetes in Canadian First Nations and non-First Nations offspring. Diabetes Care 2016;39:2240-6.

7. Wicklow BA, Sellers EAC, Sharma AK, et al. Association of gestational diabetes and type 2 diabetes exposure in utero with the development of type 2 diabetes in First Nations and non-First Nations offspring. 7 AMA Pediatr 2018;172:724-31.

8. Dart AB, Martens PJ, Rigatto C, et al. Earlier onset of complications in youth with type 2 diabetes. Diabetes Care 2014;37:436-43.

9. Pinhas-Hamiel O, Zeitler P. Acute and chronic complications of type 2 diabetes mellitus in children and adolescents. Lancet 2007;369:1823-31.

10. Truth and Reconciliation Commission: calls to action. Winnipeg: Truth and Reconciliation Commission of Canada; 2015. Available: http://trc.ca/assets/pdf/ Calls_to_Action_English2.pdf (accessed 2019 Nov. 1).

11. Walker JD, Rowe R, Jones CR. Describing the process of ethical conduct of research in an Ontario-wide First Nations diabetes research project. CMAf 2018;190(Suppl):S19-20.

12. Slater M, Green ME, Shah BR, et al. First Nations people with diabetes in Ontario: methods for a longitudinal population-based cohort study. CMAJ Open 2019; 7:E680-8.

13. Guttmann A, Nakhla M, Henderson M, et al. Validation of a health administrative data algorithm for assessing the epidemiology of diabetes in Canadian children. Pediatr Diabetes 2010;11:122-8.

14. Indian Act, RSC $1985 ; \mathrm{c} \mathrm{I}-5$.

15. Diabetes Education Resource for Children \& Adolescents (DER-CA): annual report 2018. Winnipeg: Winnipeg Regional Health Authority.

16. Shulman R, Miller FA, Stukel TA, et al. Resources and population served: a description of the Ontario Paediatric Diabetes Network. CMAJ Open 2016;4: E141-6.

17. Canadian Diabetes Association Clinical Practice Guidelines Expert Committee; Wherrett D, Huot C, Mitchell B, et al. Type 1 diabetes in children and adolescents. Can F Diabetes 2013;37(Suppl 1):S153-62.

18. Canadian Diabetes Association Clinical Practice Guidelines Expert Committee; Panagiotopoulos C, Riddell MC, Sellers EA. Type 2 diabetes in children and adolescents. Can 7 Diabetes 2013;37(Suppl 1):S163-7.

19. Slater M, Khan S, Green ME, et al. Monitoring, control and treatment of diabetes. In: Green ME, Jones CR, Walker JD, et al., editors. First Nations and diabetes in Ontario. Toronto: ICES; 2019:95-6.

20. Campbell RJ, Khan S, Slater M, et al. Diabetes and eye disease. In: Green ME, Jones CR, Walker JD, et al., editors. First Nations and diabetes in Ontario. Toronto: ICES; 2019:194.

21. Kralj B. Measuring "rurality" for purposes of health-care planning: an empirical measure for Ontario. Ont Med Rev 2000;67:33-52.

22. Oster RT, Johnson JA, Balko SU, et al. Increasing rates of diabetes amongst status Aboriginal youth in Alberta, Canada. Int 7 Circumpolar Health 2012;71: $1-7$.

23. Halipchuk J, Temple B, Dart A, et al. Prenatal, obstetric and perinatal factors associated with the development of childhood-onset type 2 diabetes. Can 7 Diabetes 2018;42:71-7.

24. Diabetes Canada Clinical Practice Guidelines Expert Committee; Panagiotopoulos C, Hadjiyannakis S, Henderson M. Type 2 diabetes in children and adolescents. Can 7 Diabetes 2018;42(Suppl 1):S247-54.

25. Griffis S, Beauvais C. A system-wide response to diabetes: networks meet the challenge. Can 7 Diabetes 2007;31:16-7.

26. Amed S, Nuernberger K, McCrea P, et al. Adherence to clinical practice guidelines in the management of children, youth, and young adults with type 1 diabetes - a prospective population cohort study. 7 Pediatr 2013;163:543-8.

27. Wang SY, Andrews CA, Gardner TW, et al. Ophthalmic screening patterns among youths with diabetes enrolled in a large US managed care network. 7AMA Ophthalmol 2017;135:432-8.

28. Jabar F, Colatruglio S, Sellers E, et al. The next generation cohort: a description of a cohort at high risk for childhood onset type 2 diabetes. 7 Dev Orig Health Dis 2019;10:24-30.

29. Dabelea D, Hanson RL, Lindsay RS, et al. Intrauterine exposure to diabetes conveys risks for type 2 diabetes and obesity: a study of discordant sibships. Diabetes 2000;49:2208-11.

30. Sellers EA, Triggs-Raine B, Rockman-Greenberg C, et al. The prevalence of the HNF-1alpha G319S mutation in Canadian aboriginal youth with type 2 diabetes. Diabetes Care 2002;25:2202-6.

31. Eskicioglu P, Halas J, Sénéchal M, et al. Peer mentoring for type 2 diabetes prevention in First Nations children. Pediatrics 2014;133:e1624-31.

32. McGavock J, Wicklow B, Dart AB. Type 2 diabetes in youth is a disease of poverty. Lancet 2017;390:1829.

33. Viner R, White B, Christie D. Type 2 diabetes in adolescents: a severe phenotype posing major clinical challenges and public health burden. Lancet 2017; 389:2252-60. 
34. Diabetes Canada Clinical Practice Guidelines Expert Committee; Crowshoe L, Dannenbaum D, Green M, et al. Type 2 diabetes and Indigenous peoples. Can 7 Diabetes 2018;42(Suppl 1):S296-306.

35. Huynh E, Rand D, McNeill C, et al. Beating diabetes together: a mixedmethods analysis of a feasibility study of intensive lifestyle intervention for youth with type 2 diabetes. Can $\mathcal{7}$ Diabetes 2015;39:484-90.

36. Diabetes Education Resource for Children \& Adolescents (DER-CA): annual report 2016. Winnipeg: Winnipeg Regional Health Authority. Available: https:// umanitoba.ca/faculties/health_sciences/medicine/units/pediatrics/media/Annual_ Report-_2016_Final_Nov_24_2017.pdf (accessed 2019 Nov. 1).

37. Trends in income-related health inequalities in Canada: methodology notes. Ottawa: Canadian Institute for Health Information; 2015.

38. Green ME, Jones CR, Walker JD, et al., editors. First Nations and diabetes in Ontario. Toronto: ICES; 2019.

Affiliations: The Hospital for Sick Children (Shulman); ICES (Shulman, Slater, Khan, Walker, Green, Frymire, Shah); Departments of Pediatrics (Shulman, Green) and Medicine (Shah), University of Toronto, Toronto, Ont.; Department of Family Medicine (Slater), Queen's University, Kingston, Ont.; Chiefs of Ontario (Jones), Toronto, Ont.; School of Rural and Northern Health (Walker), Laurentian University, Sudbury, Ont.; Memory Keepers Medical Discover Team (Jacklin), Department of Family Medicine and Biobehavioral Health, University of Minnesota Medical School, Duluth, Minn.; Health Services and Policy Research Institute (Khan, Green, Frymire), Queen's University, Kingston, Ont.; Division of Endocrinology (Shah), Sunnybrook Health Sciences Centre, Toronto, Ont.

Contributors: Carmen Jones, Michael Green, Baiju Shah, Jennifer Walker and Kristen Jacklin conceived the study. Rayzel Shulman, Baiju Shah, Carmen Jones, Kristen Jacklin, Jennifer Walker and Michael Green designed the study. Shahriar Khan analyzed the data. Rayzel Shulman drafted the manuscript. All of the authors were involved in data interpre- tation, revised the manuscript critically for important intellectual content, approved the final version to be published and agreed to be accountable for all aspects of the work.

Funding: Funding was provided by the Ontario SPOR SUPPORT Unit, which is supported by the Canadian Institutes of Health Research and the Province of Ontario. Additional support was provided to Michael Green through the Brian Hennen Chair in Family Medicine, Queen's University and to Jennifer Walker through a Tier 2 Canada Research Chair in Indigenous Health and ICES, which is funded by an annual grant from the Ontario Ministry of Health and Long-Term Care.

Acknowledgements: The authors' partner through the early design, implementation and final dissemination of this project is the Chiefs of Ontario. Their many member contributions were key to the content and quality of the project. The authors also acknowledge the members of the Patient Advisory Committee for providing insightful and thoughtful input; their advice made a substantial contribution in shaping the work. For a complete listing of the specific members of the committee, see reference 38 .

Disclaimer: This study was supported by ICES, which is funded by an annual grant from the Ontario Ministry of Health and Long-Term Care (MOHLTC). Parts of this material are based on data and information compiled and provided by the Canadian Institute for Health Information, Cancer Care Ontario and the Ontario MOHLTC. The analyses, conclusions, opinions and statements expressed in this paper are solely those of the authors and do not reflect those of the funding or data sources; no endorsement is intended or should be inferred.

Supplemental information: For reviewer comments and the original submission of this manuscript, please see www.cmajopen.ca/content/8/1/ E48/suppl/DC1. 